\title{
Unmatched clinical presentation and chest CT manifestation in a patient with severe coronavirus disease 2019 (COVID-19)
}

\author{
Bin Zhang ${ }^{1 \#}$, Jue Zhang ${ }^{2 \#}$, Hui Chen ${ }^{2}$, Ke Yang ${ }^{2}$, Shuixing Zhang ${ }^{1}$ \\ ${ }^{1}$ Department of Radiology, The First Affiliated Hospital of Jinan University, Guangzhou 510627, China; ${ }^{2}$ Department of Radiology, The First \\ People's Hospital of Tianmen City, Tianmen 431700, China \\ \#These authors contributed equally to this work.
}

Correspondence to: Ke Yang, MD, PhD. No.1 Jingling Renmin East Road, Tianmen 431700, China. Email: tmyangke2019@sina.com; Shuixing Zhang, MD, PhD. No. 613 Huangpu West Road, Tianhe District, Guangzhou 510627, China. Email: shui7515@126.com.

Submitted Feb 26, 2020. Accepted for publication Mar 23, 2020.

doi: 10.21037/qims.2020.03.12

View this article at: http://dx.doi.org/10.21037/qims.2020.03.12

An ongoing outbreak of a coronavirus disease 2019 (COVID-19) hit major cities of China, Wuhan, late December 2019 and subsequently spread to other areas of China and countries (1). As of February 16, 2020, there were 68594 confirmed cases in mainland China. Among the confirmed cases, approximately $14.0 \%$ were severe (2). The mortality rate of severe patients was $6 \%$ (3). Herein, we described the clinical characteristics and chest CT followup of a severe COVID-19 patient, whose CT appearance was only moderate, and thus represents a case of mismatch between clinical severity and chest imaging severity.

A 39-year-old man presented to the hospital on Jan 24, 2020 with a week of fever, nonproductive cough and fatigue. He lived in Wuhan before onset, with no underlying diseases. On admission, his body temperature elevated to $38.6^{\circ} \mathrm{C}\left(101^{\circ} \mathrm{F}\right)$ with rough breathing sounds. Real-time fluorescence polymerase chain reaction (RT-PCR) of the patient' throat swab was positive for 2019-nCoV nucleic acid. Laboratory findings indicated elevated C-reactive protein of $24.86 \mathrm{mg} / \mathrm{L}$ (normal rage, $0-6 \mathrm{mg} / \mathrm{L}$ ), lactic dehydrogenase of $339 \mathrm{U} / \mathrm{L}$ (normal range, 120-250 U/L), and urine protein of $1+\mathrm{g} / \mathrm{L}$. White blood cell count $\left(3.66 \times 10^{9} / \mathrm{L}\right.$; normal range, $\left.4.0-10.0 \times 10^{9} / \mathrm{L}\right)$ and lymphocyte count $\left(1.31 \times 10^{9} / \mathrm{L}\right.$; normal range, $\left.1.1-3.2 \times 10^{9} / \mathrm{L}\right)$ were normal. Liver function, myocardial enzymes and coagulation function were normal. Electrocardiogram showed sinus tachycardia.

The initial unenhanced chest CT of Jan 24, 2020 showed bilateral group-glass opacities (GGO) located in subpleural regions (4,5) (Figure 1A). The chest CT was classified at early stage. However, the patient was diagnosed as severe according to clinical criteria. The patient was treated with antiviral drugs (oseltamivir and arbidol), anti-inflammatory drugs (e.g., moxifloxacin) and mask oxygen inhalation (flow rate, 2-4 L/min). Follow-up chest CT of Jan 28, 2020 showed GGO with consolidation and air bronchogram (progressive stage) (Figure 1B). Follow-up chest CT of Jan 30, 2020 showed reduced GGO with pulmonary fibrosis (absorption stage) (Figure 1C). The patient was then at clinically severe stage for the partial arterial oxygen pressure $\left(\mathrm{PaO}_{2}\right)$ and oxygen saturation $\left(\mathrm{SO}_{2}\right)$ was $65 \mathrm{mmHg}, 92 \%$, respectively. On Feb 01, the patient's $\mathrm{PaO}_{2}$ and $\mathrm{SO}_{2}$ further decreased to $51 \mathrm{mmHg}$ and $86 \%$. The patient had no fever and cough. The repeat RT-PCR of Feb 18 was negative. The chest CT of Feb 19, 2020 showed obvious absorption of lesions (Figure 1D). The RT-PCR tests were repeated on Feb 24 and 25 and both were negative. On Feb 22, the patient's $\mathrm{SO}_{2}$ elevated to a normal value of $98 \%$. All laboratory findings were normal. Therefore, the patient met the current criteria for hospital discharge (6) and left hospital in the followed week.

This case may be an example of a group of patients who are clinically diagnosed severe but at early-stage on chest CT at presentation. Their lung diseases do not rapidly progress more than $50 \%$ within $24-48$ hours. The clinical outcomes of these patients are usually favorable. Hence, 


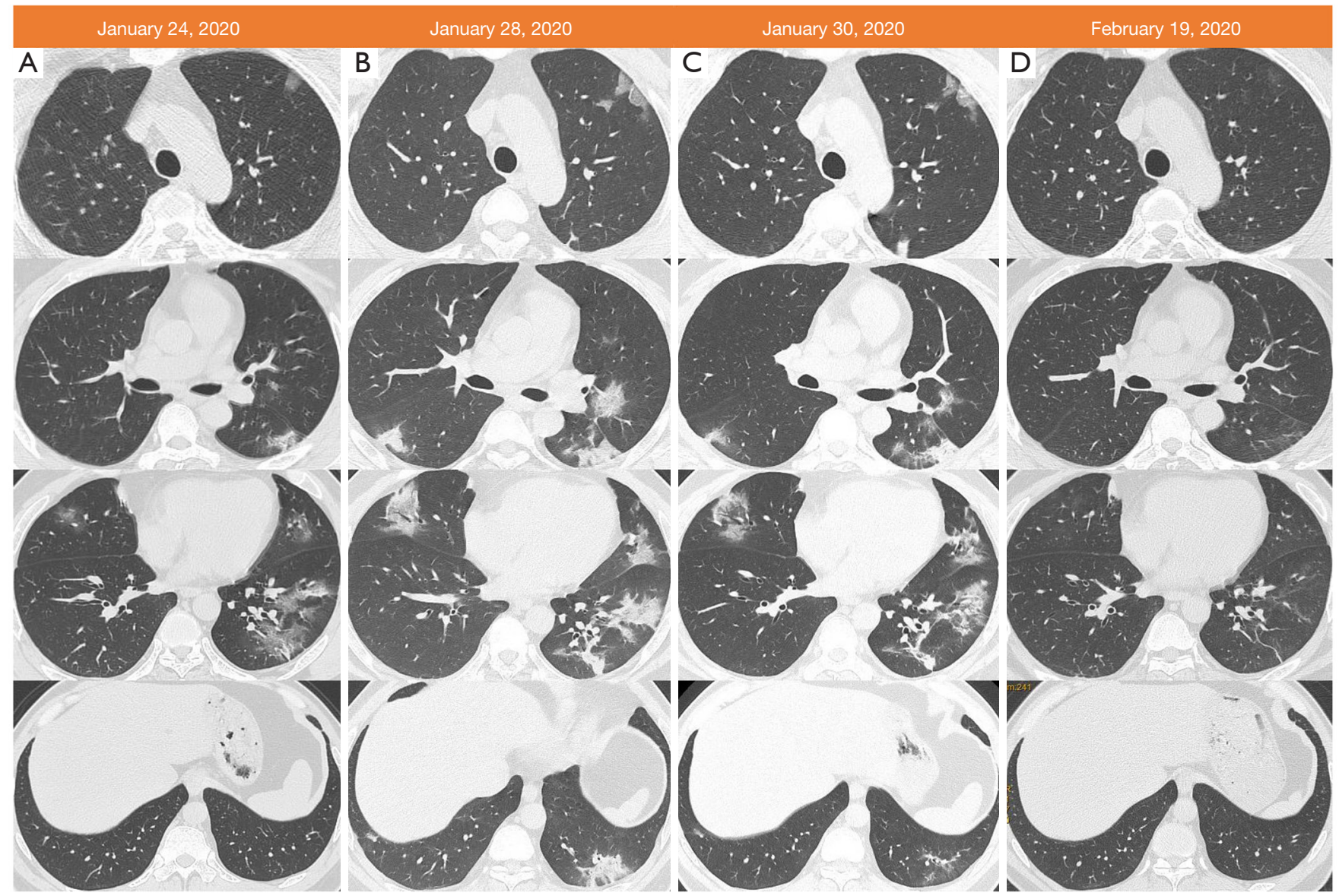

Figure 1 A 39-year-old man living in Wuhan presenting with fever and cough. (A) Axial thin-section (1 mm) non-contrast chest CT image from Jan/24/2020 shows bilateral group-glass opacities (GGO) with a peripheral distribution; (B) follow-up chest CT image on Jan/28/2020 shows GGO with consolidation; (C) follow-up chest CT image on Jan/30/2020 shows GGO and consolidation absorption; (D) follow-up chest CT image on Feb/19/2020 shows further resolution.

the stage of these patients perhaps can be down-graded, especially for patients without underlying diseases, such as chronic obstructive pulmonary disease, hypertension, and diabetes. By contrast, a recent study showed symptoms relief but progression on chest CT, indicating that clinical symptoms and imaging findings are unmatched in early stage of COVID-19 (7). Therefore, the staging of COVID-19 should consider the severity on chest imaging, which will benefit for treatments and prognosis assessment.

\section{Acknowledgments}

Thanks to all the doctors for their fighting against the COVID-19, and to the people of the country and the world for their contributions to this campaign.
Funding: None.

\section{Footnote}

Conflicts of Interest: All authors have completed the ICMJE uniform disclosure form (available at http://dx.doi. org/10.21037/qims.2020.03.12). The authors have no conflicts of interest to declare.

Open Access Statement: This is an Open Access article distributed in accordance with the Creative Commons Attribution-NonCommercial-NoDerivs 4.0 International License (CC BY-NC-ND 4.0), which permits the noncommercial replication and distribution of the article with the strict proviso that no changes or edits are made and the 
original work is properly cited (including links to both the formal publication through the relevant DOI and the license). See: https://creativecommons.org/licenses/by-nc-nd/4.0/.

\section{References}

1. Hui DS, I Azhar E, Madani TA, Ntoumi F, Kock R, Dar O, Ippolito G, Mchugh TD, Memish ZA, Drosten C, Zumla A, Petersen E. The continuing 2019-nCoV epidemic threat of novel coronaviruses to global health: the latest 2019 novel coronavirus outbreak in Wuhan, China. Int J Infect Dis 2020;91:264-6.

2. Wu Z, McGoogan JM. Characteristics of and Important Lessons From the Coronavirus Disease 2019 (COVID-19) Outbreak in China: Summary of a Report of 72314 Cases From the Chinese Center for Disease Control and Prevention. JAMA 2020. doi: 10.1001/jama.2020.2648.

3. Yang Y, Lu Q, Liu M, Wang Y, Zhang A, Neda Jalali, Natalie Dean, Ira Longini, M. Elizabeth Halloran, Xu B, Zhang X, Wang L, Liu W, Fang L. Epidemiological and clinical features of the 2019 novel coronavirus outbreak in China. medRxiv 2020.02.10.20021675; doi:10.1101/2020.0
2.10.20021675.

4. Chung M, Bernheim A, Mei X, Zhang N, Huang M, Zeng X, Cui J, Xu W, Yang Y, Fayad ZA, Jacobi A, Li K, Li S, Shan H. CT Imaging Features of 2019 Novel Coronavirus (2019-nCoV). Radiology 2020. doi: 10.1148/ radiol.2020200230.

5. Kanne JP. Chest CT Findings in 2019 Novel Coronavirus (2019-nCoV) Infections from Wuhan, China: Key Points for the Radiologist. Radiology 2020. doi: 10.1148/ radiol.2020200241.

6. China National Health Commission. Diagnosis and treatment of 2019-nCoV pneumonia in China. In Chinese. Published February 8, 2020. Accessed February 28, 2020. Available online: http://www.nhc.gov.cn/yzygj/ s7653p/202002/d4b895337e19445f8d728fcaf1e3e13a. shtml

7. Hu X, Chen J, Jiang X, Tao S, Zhen Z, Zhou C, Wang J. CT imaging of two cases of one family cluster 2019 novel coronavirus (2019-nCoV) pneumonia: inconsistency between clinical symptoms amelioration and imaging sign progression. Quant Imaging Med Surg 2020;10:508-10.

Cite this article as: Zhang B, Zhang J, Chen H, Yang K, Zhang S. Unmatched clinical presentation and chest CT manifestation in a patient with severe coronavirus disease 2019 (COVID-19). Quant Imaging Med Surg 2020;10(4):871-873. doi: 10.21037/qims.2020.03.12 